\title{
SIMS Characterization of
} Amorphous Silicon Germanium Alloys Grown by Hot-Wire Deposition

R.C. Reedy, A.R. Mason, B.P. Nelson, and Y. Xu National Renewable Energy Laboratory

Presented at the National Center for Photovoltaics Program Review Meeting Denver, Colorado

September 8-11, 1998

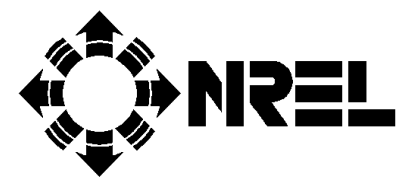

National Renewable Energy Laboratory 1617 Cole Boulevard

Golden, Colorado 80401-3393

A national laboratory of the U.S. Department of Energy Managed by Midwest Research Institute for the U.S. Department of Energy under contract No. DE-AC36-83CH10093

Work performed under task number PV903301

October 1998 


\section{NOTICE}

This report was prepared as an account of work sponsored by an agency of the United States government. Neither the United States government nor any agency thereof, nor any of their employees, makes any warranty, express or implied, or assumes any legal liability or responsibility for the accuracy, completeness, or usefulness of any information, apparatus, product, or process disclosed, or represents that its use would not infringe privately owned rights. Reference herein to any specific commercial product, process, or service by trade name, trademark, manufacturer, or otherwise does not necessarily constitute or imply its endorsement, recommendation, or favoring by the United States government or any agency thereof. The views and opinions of authors expressed herein do not necessarily state or reflect those of the United States government or any agency thereof.

Available to DOE and DOE contractors from:

Office of Scientific and Technical Information (OSTI)

P.O. Box 62

Oak Ridge, TN 37831

Prices available by calling 423-576-8401

Available to the public from:

National Technical Information Service (NTIS)

U.S. Department of Commerce

5285 Port Royal Road

Springfield, VA 22161

703-605-6000 or 800-553-6847

or

DOE Information Bridge

http://www.doe.gov/bridge/home.html 


\title{
SIMS Characterization of Amorphous Silicon Germanium Alloys Grown by Hot-Wire Deposition
}

\author{
R.C. Reedy, A.R. Mason, B.P. Nelson and Y. Xu \\ National Renewable Energy Laboratory \\ 1617 Cole Blvd., Golden, CO 80401
}

\begin{abstract}
In this paper, we present methods for the quantitative secondary ion mass spectrometry (SIMS) characterization of amorphous SiGe:H alloy materials. A set of samples was grown with germanium content ranging from 5\% to $77 \%$ and was subsequently analyzed by electron probe X-ray microanalysis (EPMA) and nuclear reaction analysis (NRA). Calibration of the SIMS quantification was performed with respect to EPMA data for germanium and NRA data for hydrogen.
\end{abstract}

\section{INTRODUCTION}

Silicon germanium alloys are commonly used in a-SiH-based photovoltaic devices to reduce the optical bandgap. It is known that a-SiH materials with excellent electronic and structural properties can be grown by the hot-wire chemical-vapor deposition (HWCVD) process. This process was recently used to investigate the possibility of growing a-SiGe:H at a high deposition rate with properties superior to that of plasma-enhanced chemical-vapor deposition (PECVD) [1].

Secondary ion mass spectrometry (SIMS) analysis is indispensable in the characterization of thin films. Not only is it one of the few techniques that can detect elements of low mass, but it is also useful in providing impurity information at levels in the low parts per billion. Much work has been done with SIMS in the characterization of HWCVD a-Si:H materials. SIMS depth profiles of hydrogen, in conjunction with changes in growth parameters and treatments, have helped to improve the properties of these films. The purpose of these experiments is to develop methods for characterizing the germanium-containing material.

\section{EXPERIMENT PROCEDURE}

The silicon germanium alloy samples were grown by the HWCVD process using silane and germane gas mixtures. Electron probe X-ray microanalysis (EPMA) of these samples was performed with a 5-keV electron beam. Atomic ratios were calculated for $\mathrm{Si}$ and $\mathrm{Ge}$. The depth of measurement is estimated to be between 0.25 and $0.5 \mu \mathrm{m}$. Hydrogen concentrations were measured by nuclear reaction analysis (NRA). Measurements were made at four different 
beam energies $(6.6,6.8,7.0$, and $7.2 \mathrm{MeV})$ corresponding to four different depths within the films.

The SIMS measurements were carried out using a Cameca IMS-5F instrument. A beam of $\mathrm{Cs}^{+}$, purified by a mass filter, was used as the source of the primary ions. The impact energy of the primary ion beam was $14.5 \mathrm{keV}$ at an incident angle of $25^{\circ}$ from the surface normal. The primary current was $100 \mathrm{nA}$. A square area of $150 \mu \mathrm{m}$ x $150 \mu \mathrm{m}$ was raster-scanned. Negative secondary ions generated from the sample were accelerated normal to its surface and were detected at $4.5 \mathrm{keV}$. Secondary ions were collected from a $60-\mu \mathrm{m}$ diameter area in the center of the raster-scanned area to minimize effects from the crater walls. In the sample chamber, a cryoshield at liquid nitrogen temperature was used, and the working pressure was $2 \times 10^{-10}$ torr. Secondary ions were counted by an electron multiplier detector.

\section{QUANTIFICATION}

Calibration is performed by measuring ion implant standards to obtain relative sensitivity factors or RSFs [2]. Quantification of an element of interest (E) is obtained by applying these RSFs to the ratio of secondary ion intensities:

$$
C_{E}=\left(R S F_{E}\right) I_{E} / I_{M}
$$

where:

$\mathrm{C}_{\mathrm{E}}=$ concentration of $\mathrm{E}$,

$\mathrm{RSF}_{\mathrm{E}}=$ relative sensitivity factor for $\mathrm{E}$ (corrected for isotopic abundance),

$\mathrm{I}_{\mathrm{E}} \quad=\quad$ secondary ion intensity for $\mathrm{E}$, and

$\mathrm{I}_{\mathrm{M}} \quad=\quad$ secondary ion intensity for $\mathrm{M}$ (matrix, e.g., silicon in this case).

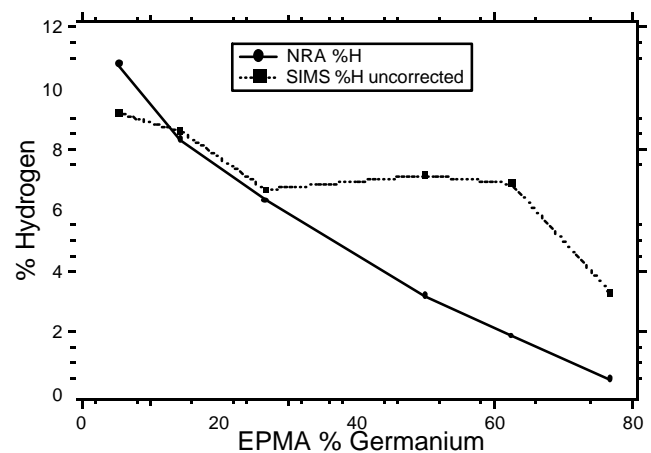

FIGURE 1. SIMS quantification of H compared to NRA data.

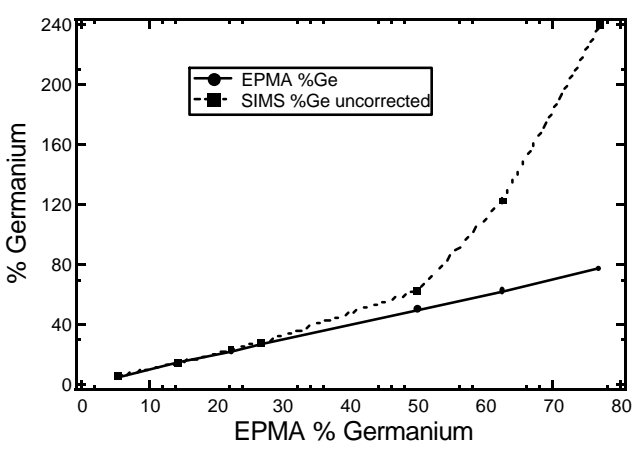

FIGURE 2. SIMS quantification of Ge compared to EPMA data. 
This procedure is commonly used in SIMS quantification where the element of interest is less than the "dilute limit" (1\% atomic density). However, in cases of alloyed matrices, correction factors must be applied:

$$
C_{G e 2}=\left(100 * C_{G e 1}\right) /\left(100+C_{G e 1}\right)
$$

where:

$\mathrm{C}_{\mathrm{Ge} 1}=$ concentration of Ge after quantification, and

$\mathrm{C}_{\mathrm{Ge} 2}=$ concentration of $\mathrm{Ge}$ after alloy correction.

Secondary ion yields for a given element can change by orders of magnitude between matrices, which are reflected in differences in RSFs. For example, the RSF for $\mathrm{Cr}$ in germanium is $2.5 \times 10^{20}$ versus $6.5 \times 10^{21}$ in silicon. Measuring the $\mathrm{H}$ and $\mathrm{Ge}$ after alloy correction, and then comparing 6 or 7 data points to NRA data for $\mathrm{H}$ and EPMA data for Ge generated the RSF correction factors. Linear regression was performed to find the best fit between the SIMS, EPMA, and NRA data. The slope (m) and intercept (b) values from the calibration curve were then used for RSF correction.

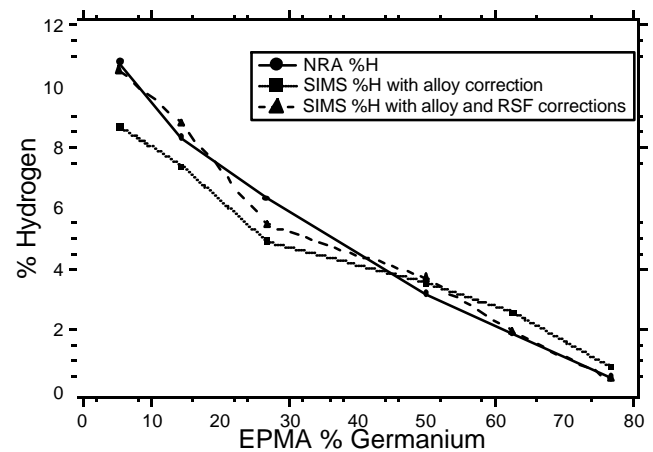

FIGURE 3. SIMS H after alloy correction and RSF correction compared to NRA results.

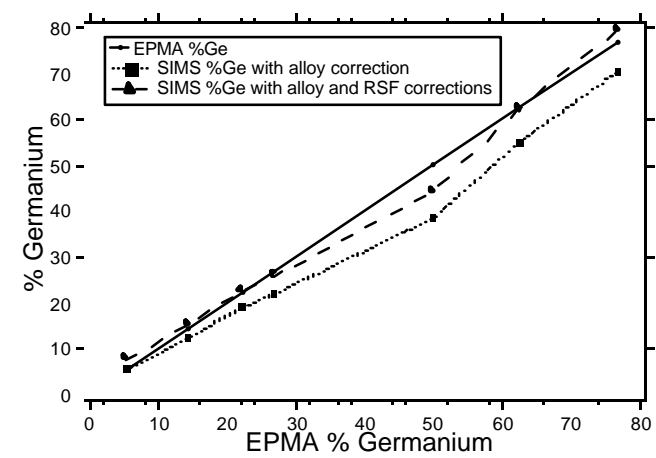

FIGURE 4. SIMS Ge after alloy correction and RSF correction compared to EPMA results.

\section{DISCUSSION}

SIMS is generally stated to be accurate to a factor of two. This is insignificant when considering the great dynamic range of the technique, e.g., some impurities can be detected at levels of parts per billion. However, maximum precision and reproducibility are always desired in any characterization technique. Substrate material, density of the films, oxygen content, resistivity, and sample holders may all contribute to loss of accuracy. 
Samples for SIMS were deposited on single-polished crystalline silicon (c-Si), whereas samples for NRA were deposited on double-polished c-Si, and samples for EPMA were deposited on glass. Slight differences may exist between samples.

The SIMS and EPMA analysis performed is based on the atomic density of crystalline silicon, $5 \times 10^{22}$ atoms $/ \mathrm{cm}^{3}$. The density of the a-SiGe:H material is less than $5 \times 10^{22}$ atoms $/ \mathrm{cm}^{3}$ and is dependent on growth conditions. Variations in density may affect the ionization efficiency of elements of interest and may not change proportionally.

Non uniform oxygen distribution, between samples and within each sample, might have an effect on the NRA data. EPMA detected oxygen $(>0.1 \%)$ in most samples, which would imply it is greater than the SIMS quantification. Oxygen at such high levels in the films might affect the ionization efficiency of $\mathrm{Si}$ and Ge. In analyzing these samples with $\mathrm{Cs}^{+}$, the detection of positive molecular $\left(\mathrm{M}+\mathrm{Cs}^{+}\right)$ ions might alleviate some of these matrix effects.

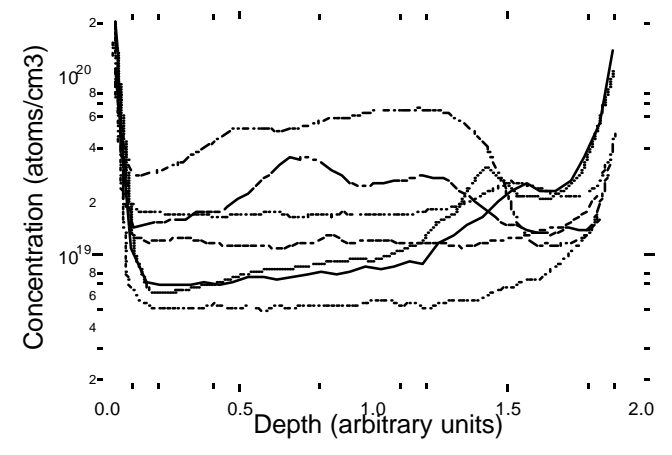

FIGURE 5. Distribution of oxygen versus depth as measured by SIMS.

The a-SiGe:H materials were provided undoped and may be slightly resistive. The analysis of resistive materials by SIMS is especially difficult when sputtering with a $\mathrm{Cs}^{+}$primary beam and biasing the sample negative to analyze negative secondary ions. Depositing thin layers of metal on the surface or flooding the sample with electrons are the two most common approaches to preventing charge build-up. However, depositing metals alters the surface and usually adds contamination. Flooding the sample with electrons increases the background in the instrument because of hydrogen desorption.

SIMS analysts in the semiconductor industry have demonstrated highly reproducible measurements with high-precision sample holders [3]. Analyzing a sample in the same window of the same sample holder is essential for these measurements. Unfortunately, it is not always feasible to characterize one sample at a time, considering the time it takes to achieve high vacuum after sample loading.

\section{CONCLUSION}

SIMS measurements of hydrogen can be performed on these materials within the generally stated accuracy of $50 \%$, or in this case, 15\%. Compositional analysis of alloys, most often accomplished by Auger electron spectroscopy and EPMA, can also be performed by SIMS to 
an accuracy of $50 \%$. Furthermore, if the SIMS measurement of Ge at $7.6 \%$ in the $5 \% \mathrm{Ge}$ sample is disregarded, the accuracy for Ge is within $15 \%$. Closer attention to the factors listed above may improve the accuracy of this technique.

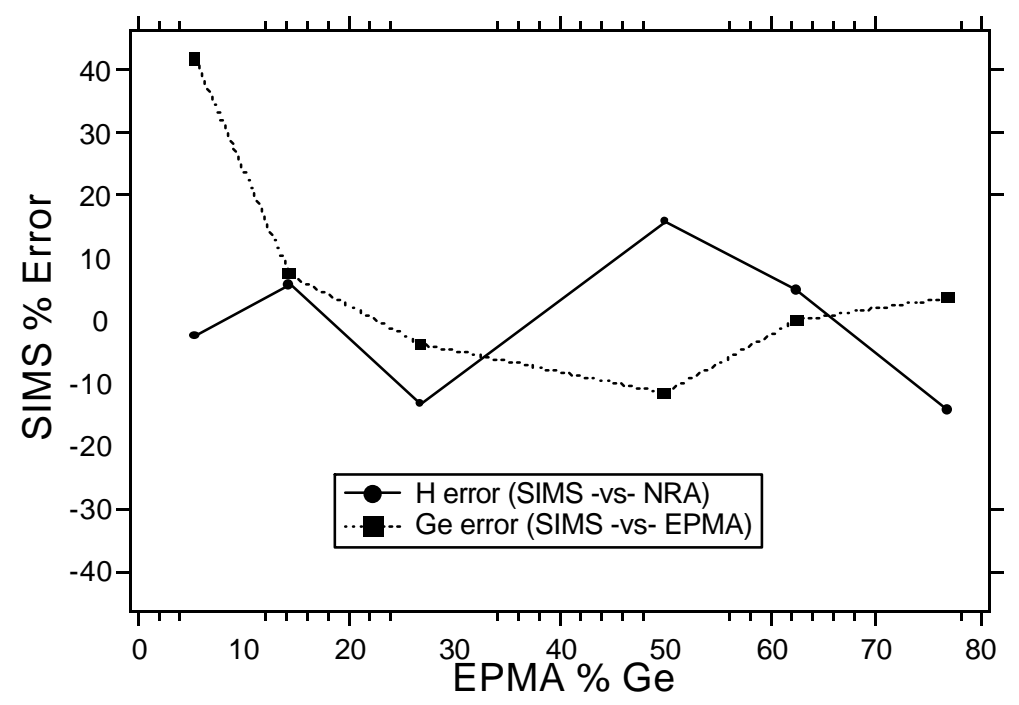

FIGURE 5. Percent error in SIMS measurements (after corrections) when compared to EPMA and NRA results.

\section{ACKNOWLEDGEMENTS}

We gratefully acknowledge William A. Lanford at the University of Albany, New York, for the NRA analysis of these samples. This work was performed under Contract No. DE-AC3683CH10093 with the U.S. Department of Energy.

\section{REFERENCES}

1. B.P. Nelson, Y. Xu, D.L. Williamson, B. von Roedern, A.R. Mason, S. Heck, A.H. Mahan, S.E. Schmitt, A.C. Gallager, J. Webb, and R. Reedy, Amorphous and Microcrystalline Silicon Technology 507, (Materials Research Society, Pittsburgh, 1998), in press.

2. R.G. Wilson, F.A. Stevie, and C.W. Magee, Secondary Ion Mass Spectrometry, A Practical Handbook for Depth Profiling and Bulk Impurity Analysis (John Wiley \& Sons, New York, 1989), p. 3.1-1.

3. C.M. Jones and F.L. Morgan, Proceedings SIMS XI (John Wiley \& Sons, New York, 1998), p. 721. 